\title{
HIV in Canada—surveillance report, 2019
}

\author{
Nisrine Haddad ${ }^{1}$, Ashley Weeks' ${ }^{1}$, Anita Robert ${ }^{1}$, Stephanie Totten ${ }^{1}$
}

\begin{abstract}
Background: Human immunodeficiency virus (HIV) is a global public health issue. HIV has been nationally notifiable in Canada since 1985. The Public Health Agency of Canada (PHAC) monitors trends in new HIV diagnoses.
\end{abstract}

Objectives: The objective of this surveillance report is to provide an overview of the epidemiology of reported HIV cases in 2019 in Canada. The report highlights 10-year trends (2010-2019). Data on HIV diagnosed through Immigration Medical Exams (IME) and trends in perinatal transmission of HIV are also presented.

Methods: PHAC monitors HIV through the HIV/AIDS Surveillance System, a passive, case-based system that collates non-nominal data submitted voluntarily by all Canadian provinces and territories. Descriptive analyses were conducted on national data. IME data were obtained from Immigration, Refugees and Citizenship Canada (IRCC), and data on HIV-exposed pregnancies were obtained through the Canadian Perinatal HIV Surveillance Program.

Results: In 2019, a total of 2,122 HIV diagnoses were reported in Canada (5.6 per 100,000 population). Saskatchewan reported the highest provincial diagnosis rate at 16.9 per 100,000 population. The 30 to 39 -year age group had the highest HIV diagnosis rate at 12.7 per 100,000 population. While the rates for both males and females fluctuated in the past decade, since 2010 the rates among males decreased overall, while the rate among females increased slightly. As in previous years, the diagnosis rate for males in 2019 was higher than that for females ( 7.9 versus 3.4 per 100,000 population, respectively). The highest proportion of all reported adult cases with known exposure were gay, bisexual and other men who have sex with men (gbMSM, 39.7\%), followed by cases attributed to heterosexual contact $(28.3 \%)$ and among people who inject drugs (PWID, 21.5\%). The number of migrants who tested positive for HIV during an IME conducted in Canada was 626. The one documented perinatal HIV transmission related to a mother who had not received antepartum or intrapartum antiretroviral therapy prophylaxis.

Conclusion: The number and rate of reported HIV cases in Canada has remained relatively stable over the last decade, with minor year-to-year variations. As in previous years, the gbMSM and PWID populations represent a high proportion of HIV diagnoses, although a sizable number of cases were attributed to heterosexual contact. It is important to routinely monitor trends in HIV in light of pan-Canadian commitments to reduce the health impact of sexually transmitted and blood-borne infections by 2030 .
Suggested citation: Haddad N, Weeks A, Robert A, Totten S. HIV in Canada-surveillance report, 2019. Can Commun Dis Rep 2021;47(1):77-86. https://doi.org/10.14745/ccdr.v47i01a11

Keywords: HIV, surveillance, gay, bisexual and other men who have sex with men, heterosexual contact, people who inject drugs, perinatal HIV, Canada

\section{Introduction}

Human immunodeficiency virus (HIV) has a serious economic and social impact globally; an estimated 1.7 million people worldwide were newly infected with HIV in 2019 (1). In Canada, recent estimates indicate that approximately 62,050 people were living
This work is licensed under a Creative Commons Attribution 4.0 International License.

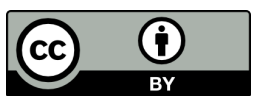

Affiliation

${ }^{1}$ Centre for Communicable Diseases and Infection Control, Public Health Agency of Canada, Ottawa, ON

\section{Correspondence:}

phac.hass.aspc@canada.ca with HIV at the end of 2018. Of the people living with HIV, $87 \%$ were diagnosed; $85 \%$ of those diagnosed were on treatment, and $94 \%$ of the people receiving treatment had an undetectable viral load (2). 
information on data elements including but not limited to age, sex, race/ethnicity and risks associated with the transmission of HIV (exposure categories). These data are voluntarily submitted to PHAC by provincial and territorial public health authorities.

Data on exposure category and race/ethnicity are submitted with varying degrees of completeness across the country. Exposure category data were reported by all jurisdictions except for Québec; by province and territory, completeness of data ranged from $68.6 \%$ to $100 \%$ in 2019 ( $57.1 \%$ overall). Race/ethnicity data were submitted by all jurisdictions except Québec and British Columbia; for those who did report race/ethnicity data, the completion rate ranged from $22 \%$ to $100 \%$ ( $41.5 \%$ overall). Newfoundland and Labrador, Yukon and Nunavut submitted race/ethnicity information for all reported cases. Northwest Territories did not have any diagnosed cases of HIV in 2019. In 2019, Saskatchewan submitted only two race/ethnicity subcategories, Indigenous and non-Indigenous. New Brunswick submitted only one subcategory for race/ethnicity category, whether a case was First Nations, and did not provide information on any other race/ethnicity category.

Data in each province and territory are obtained through provincial HIV surveillance systems, which may include both public health and laboratory reporting. Each province or territory provides data to PHAC either through the National Case Report Form (12) or through a secure electronic dataset transmission. All raw data (paper forms and electronic datasets) are retained in compliance with the Directive for the Collection, Use and Dissemination of Information relating to Public Health (PHAC, 2013, unpublished document). Data quality assessment, such as the detection of duplicate entries, is handled by the provinces and territories prior to submission to PHAC.

The objectives of this surveillance report are to provide updates on the epidemiology of reported HIV cases in Canada from 2010 to the end of 2019, by geographic location, age group, sex and exposure category. In addition, updated information on immigration medical screening results for HIV and on the number of infants perinatally exposed and infected with HIV are presented.

\section{Methods}

\section{Data sources}

This HIV surveillance report uses data from three different sources: the national HIV/AIDS Surveillance System (HASS) maintained by PHAC; immigration medical screening for HIV by Immigration, Refugees and Citizenship Canada (IRCC); and the Canadian Perinatal HIV Surveillance Program (CPHSP). Details on each data source are outlined below.

\section{HIV/AIDS Surveillance System}

HASS is a passive, case-based surveillance system that collates non-nominal data on people diagnosed with HIV infection who meet the national case definition (11). PHAC receives
The data in this surveillance report represent newly reported HIV cases diagnosed on or before December 31, 2019, that were submitted by provincial and territorial surveillance programs to PHAC up to September $18^{\text {th }}, 2020$, and validated as of October 8, 2020. Additional details on HASS methods can be found elsewhere (12).

Alberta and British Columbia resubmitted revised historical data since 2016 and 2017, respectively. This year, Ontario resubmitted updated historical data since 1985.

\section{Immigration medical screening for HIV}

All foreign nationals applying for permanent residence and some applying for temporary residence in Canada must undergo an IME administered by third-party panel physicians on behalf of IRCC, either in Canada or overseas. All applicants aged 15 years and older are screened for HIV during the IME. IRCC provides PHAC with non-nominal data collected during the IME on migrants who tested positive for HIV. The term "migrant" is used broadly and includes the following: immigrants (permanent residents in the economic and family classes); refugees (resettled refugees, protected persons and asylum claimants); and 
temporary residents (visitors, international students, temporary foreign workers and temporary resident permit holders). The IME data presented here were obtained from IRCC's Global Case Management System, which contains the IME information for all applicants screened in Canada or overseas who tested positive for HIV. Aggregate data were provided to PHAC in July 2020. Data on individuals tested in Canada were obtained from IMEs conducted in 2019. Data concerning individuals tested overseas were obtained from individuals with an HIV diagnosis on their IME who landed in Canada in 2019.

IRCC shares nominal data from overseas IME test results with participating provinces and territories for all clients who have been diagnosed with HIV and have a valid Canadian residential address on file that indicates their current province/territory of residence. This supports the continuity of care for clients with HIV. These data are incorporated into the provincial/territorial routine HIV case-based surveillance systems to varying degrees, with some jurisdictions reporting these HIV-positive migrant cases as a new diagnosis and others excluding them from provincial/territorial reporting to PHAC.

\section{Canadian Perinatal HIV Surveillance Program}

National data on the HIV status of infants exposed perinatally to HIV infection are collected through the CPHSP, an initiative of the Canadian Paediatric AIDS Research Group. The CPHSP is a sentinel-based active surveillance system that collects data on two groups of children: infants born to HIV-positive women and HIV-infected children receiving care at any participating site (whether born in Canada or abroad). Additional information on CPHSP methods are provided elsewhere $(10,12)$. Surveillance data for 2019, including data updates for previous years, were submitted to PHAC in March 2020.

\section{Analysis}

We used all HIV case data reported to HASS to complete descriptive analyses for overall trends, geographic location, sex, age and exposure category. Analyses were restricted to cases for which data were available (i.e. not missing). Counts and proportions were calculated from IRCC data. The CPHSP provided aggregated data tables, and selected results are presented in this report.

Microsoft Excel 2016 (Redmond, Washington, United States) and SAS Enterprise Guide v7.1 (Cary, North Carolina, United States) software were used for data cleaning and analysis. Standardized data recoding procedures were applied to all submitted provincial and territorial datasets to create a national dataset for analysis. In this report, the term "adult" is defined as anyone aged 15 years or older. The surveillance data presented in this report were validated by all provinces and territories to ensure accuracy.

No statistical procedures were used for comparative analysis, nor were any statistical techniques applied to account for missing data since analyses were limited to cross-tabulations due to the descriptive nature of the analysis. The population data source used to calculate rates was the Annual Demographic Statistics, issued by Statistics Canada in July 2019 (13).

Supplementary tables are listed in the Appendix and are available upon request.

\section{Results}

\section{Overall trends}

A cumulative total of 88,357 HIV diagnoses have been reported to PHAC since HIV reporting began in Canada in 1985. In 2019, a total of 2,122 HIV diagnoses were reported. The national diagnosis rate was 5.6 per 100,000 population. This rate has slightly decreased since 2010 when it was 6.3 per 100,000 population (Figure 1).

Figure 1: Number of reported cases of HIV and diagnosis rates overall, by sex and year, Canada, 2010-2019a,b

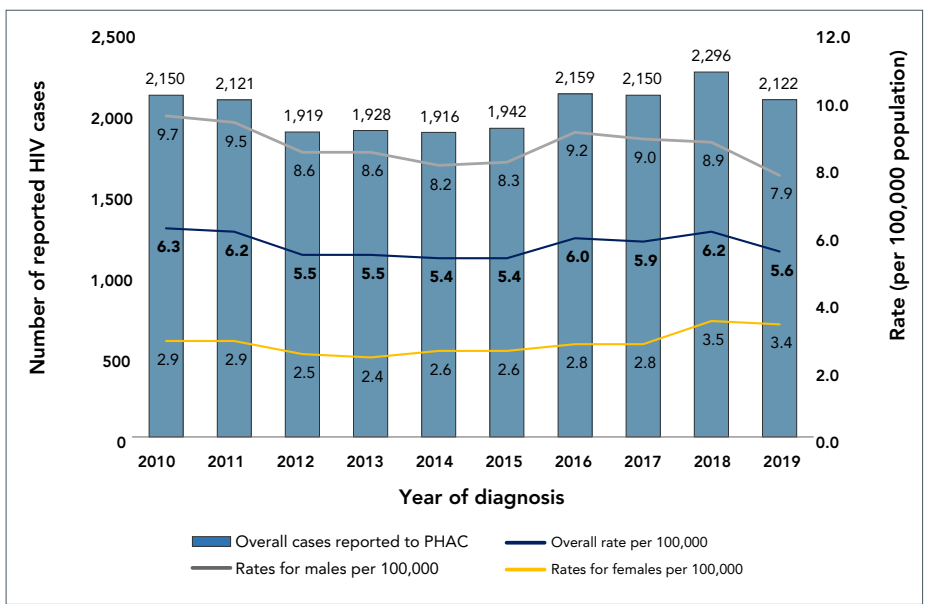

Abbreviations: HIV, human immunodeficiency virus; PHAC, Public Health Agency of Canada a Population data source: Annual Demographic Statistics, Demography Division, Statistics Canada, July 1, 2019

${ }^{b}$ Overall rate excludes cases where sex is transgender, transsexual, not reported or unknown

In 2019, the diagnosis rate for males was 7.9 per 100,000 population and for females was 3.4 per 100,000 population. While the rates for both males and females fluctuated in the past decade, the rates in the male population decreased slightly since 2016 (from 9.2 to 7.9 per 100,000 population) and increased slightly in females since 2015 (from 2.6 to 3.4 per 100,000 population) (Figure 1).

\section{Geographic distribution}

In 2019, Saskatchewan had the highest provincial/territorial diagnosis rate at 16.9 per 100,000 population. Manitoba had the second highest provincial/territorial diagnosis rate at 8.8 per 100,000 population, followed by Québec, Alberta, Ontario and 
Figure 2: HIV diagnosis rate (per 100,000 population), by province and territory, Canada, 2019a,b

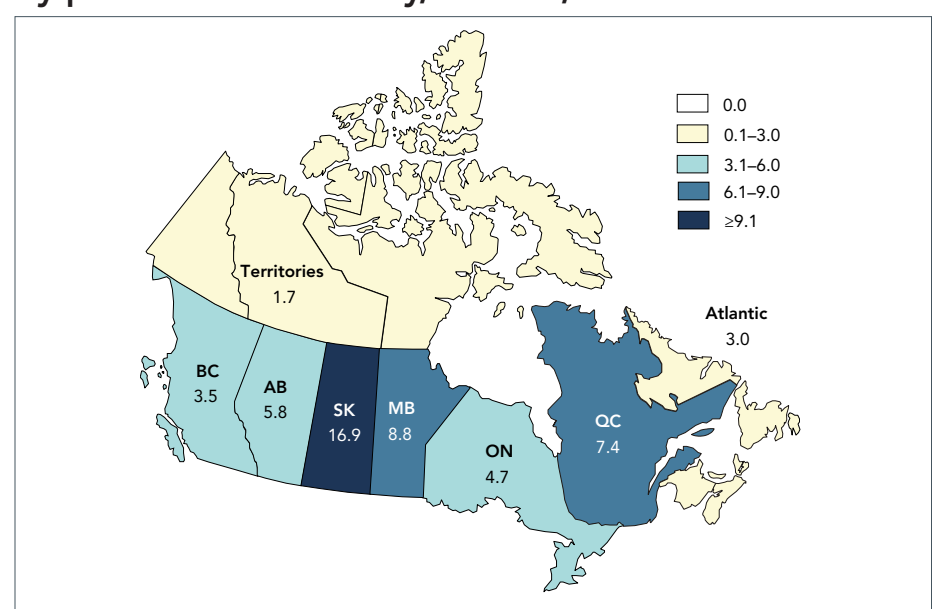

Abbreviations: $A B$, Alberta; $B C$, British Columbia; HIV, human immunodeficiency virus; MB, Manitoba; ON, Ontario; QC, Québec; SK, Saskatchewan

a Rates for the territories (Northwest Territories, Nunavut, Yukon) and Atlantic region (New Brunswick, Newfoundland and Labrador, Nova Scotia, Prince Edward Island) are presented as averages

${ }^{b}$ National rate of 5.6 cases per 100,000 population

British Columbia at 7.4, 5.8, 4.7 and 3.5 per 100,000 population, respectively (Figure 2 ).

\section{Age and sex distribution}

In 2019 , data on age groups were available for almost $100 \%$ $(n=2,120)$ of all reported HIV diagnoses. The diagnosis rate by age group has remained stable since 2010 for those aged younger than 19 years and those aged 50 years and older. The diagnosis rate has fluctuated slightly over the past 10 years for those in the 20 to 29,30 to 39 and 40 to 49 -year age groups. The 30 to 39-year age group had the highest diagnosis rate throughout the 10-year period; in 2019, the rate was 12.7 per 100,000 population, an overall decrease from 14.3 per 100,000 population in 2010. The 20 to 29-year age group had the second highest rate at 10.1 per 100,000 population in 2019 , followed by the 40 to 49 -year age group at 9.1 per 100,000 population. In 2019, diagnostic rates of those aged 50 years and older were 3.2 per 100,000 population and of those aged 15 to 19 years were 1.6 per 100,000 population; children less than 15 years old had the lowest diagnostic rate of 0.2 per 100,000 population (Figure 3).

In 2019, data on sex were available for almost $100 \%$ of all reported HIV diagnoses $(n=2,118)$. Males accounted for $69.8 \%$ of the diagnoses where sex was known, while females accounted for $30.2 \%$.

As in previous years, males aged 30 to 39 years old had the highest diagnosis rates in 2019 , at 16.8 per 100,000 population; this age group also had the highest rates among females, at 8.4 per 100,000 population. Among both sexes, the bulk of HIV diagnoses occurred in those aged 20 to 49 years old. In all
Figure 3: HIV diagnosis rate, all ages, by age group and year, Canada, 2010-2019a,b,c

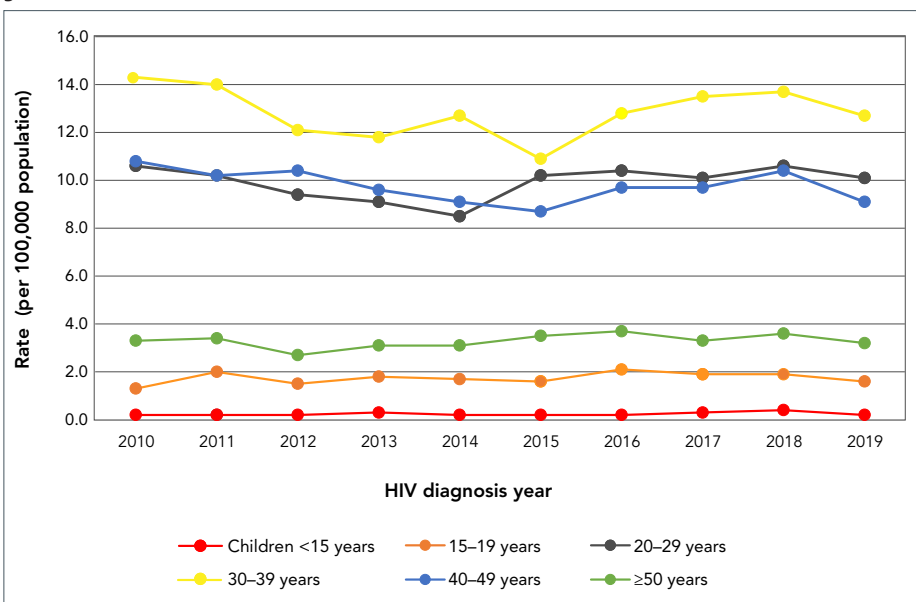

Abbreviation: HIV, human immunodeficiency virus

Excludes cases where sex is transsexual, transgender, not reported or unknown

b Excludes cases where age is not reported or unknown

Population data source: Annual Demographic Statistics, Demography Division, Statistics Canada July 1, 2019

Figure 4: HIV diagnosis rate, all ages, by sex and age group, Canada, 2019a,b,c

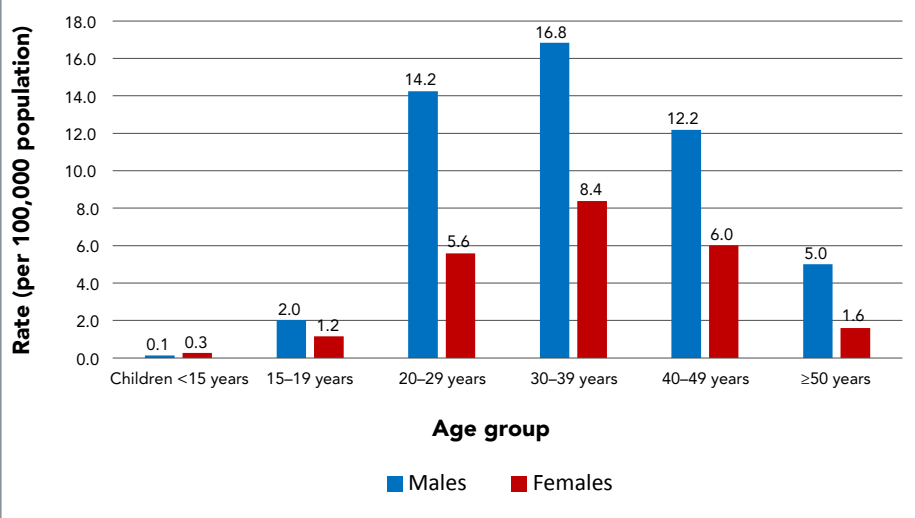

Abbreviation: HIV, human immunodeficiency virus

axcludes cases where sex is transsexual, transgender, not reported or unknown

Excludes cases where age is not reported or unknown

Population data source: Annual Demographic Statistics, Demography Division, Statistics Canada July 1, 2019

age groups, except for those younger than 19 years old, rates among males were at least twice as high as among their female counterparts (Figure 4).

\section{Race/ethnicity}

Race/ethnicity information was known for 880 cases $(41.5 \%)$ in 2019. Of cases with known race/ethnicity, $30.7 \%$ were reported as White, $25.5 \%$ as Black and $24.7 \%$ as Indigenous (First Nations, Inuit, Métis or Indigenous not otherwise specified). The distribution of race/ethnicity categories varied by sex; among males, the highest proportion was reported as White (38.5\%), while females were mainly reported as Black, at $42.1 \%$, and Indigenous, at 40\% (Table 1). 
Table 1: Number and percentage distribution of HIV cases (all ages) by sex and race/ethnicity, Canada, $2019^{a, b}$

\begin{tabular}{|c|c|c|c|c|c|c|}
\hline \multirow{3}{*}{ Race/ethnicity } & \multicolumn{4}{|c|}{ HIV cases } & \multirow{2}{*}{\multicolumn{2}{|c|}{ Total ${ }^{c}$}} \\
\hline & \multicolumn{2}{|c|}{ Male } & \multicolumn{2}{|c|}{ Female } & & \\
\hline & $n$ & $\%$ & $n$ & $\%$ & $\mathbf{n}$ & $\%$ \\
\hline Indigenous & 104 & 17.4 & 112 & 40.0 & 217 & 24.7 \\
\hline First Nations & 45 & 7.5 & 46 & 16.4 & 92 & 10.5 \\
\hline Métis & 4 & 0.7 & 0 & 0.0 & 4 & 0.5 \\
\hline Inuit & 2 & 0.3 & 0 & 0.0 & 2 & 0.2 \\
\hline $\begin{array}{l}\text { Indigenous, not } \\
\text { otherwise specified }\end{array}$ & 53 & 8.9 & 66 & 23.6 & 119 & 13.5 \\
\hline $\begin{array}{l}\text { South Asian/West Asian/ } \\
\text { Arabd }^{d}\end{array}$ & 38 & 6.4 & 4 & 1.4 & 42 & 4.8 \\
\hline Asian $^{e}$ & 42 & 7.0 & 3 & 1.1 & 45 & 5.1 \\
\hline Black $^{\dagger}$ & 106 & 17.7 & 118 & 42.1 & 224 & 25.5 \\
\hline Latin Americang & 62 & 10.4 & 2 & 0.7 & 64 & 7.3 \\
\hline White & 230 & 38.5 & 39 & 13.9 & 270 & 30.7 \\
\hline Otherh & 16 & 2.7 & 2 & 0.7 & 18 & 2.0 \\
\hline Subtotal ${ }^{\mathrm{b}}$ & 598 & 40.5 & 280 & 43.8 & 880 & 41.5 \\
\hline Not reported & 880 & 59.5 & 359 & 56.2 & 1,242 & 58.5 \\
\hline Total & 1,478 & N/A & 639 & N/A & 2,122 & N/A \\
\hline $\begin{array}{l}\text { Abbreviations: HIV, human immunoc } \\
\text { a Race/ethnicity information is not su } \\
\text { jurisdictions, completion rate varies, } \\
\text { b All percentages are calculated usin } \\
\text { for which data were available) } \\
\text { c Total includes cases where sex is tr } \\
\text { d For example, Armenian, Banglade } \\
\text { Sri Lankan } \\
\text { - For example, Cambodian, Chinese } \\
\text { Vietnamese } \\
\text { f For example, Haitian, Jamaican an } \\
\text { g For example, Central American, M } \\
\text { h Includes mixed raced and any othe }\end{array}$ & $\begin{array}{l}\text { Eency virus } \\
\text { itted by } Q \\
\text { erpret data } \\
\text { e subtotal } \\
\text { sexual, trar } \\
\text { Egyptian, I } \\
\text { ipino, Indo } \\
\text { mali } \\
\text { an and So } \\
\text { tegories }\end{array}$ & $\begin{array}{l}; \text { N/A, no } \\
\text { uébec or } \\
\text { ith caa } \\
\text { value as } \\
\text { isgender } \\
\text { ranian, L } \\
\text { nesian, J } \\
\text { uth Ame }\end{array}$ & $\begin{array}{l}\text { t applic } \\
\text { British } \\
\text { ition } \\
\text { a deno } \\
\text { and cas } \\
\text { ebanese } \\
\text { apanes } \\
\text { ican }\end{array}$ & $\begin{array}{l}\text { ble } \\
\text { olumbia; } \\
\text { inator (in } \\
\text { s where } \\
\text { Morocca } \\
\text { Korean, }\end{array}$ & $\begin{array}{l}\text { for other } \\
\text { cluding only } \\
\text { ex was not } \\
\text {, Pakistani } \\
\text { aotian and }\end{array}$ & $\begin{array}{l}\text { cases } \\
\text { eported } \\
\text { and }\end{array}$ \\
\hline
\end{tabular}

\section{Exposure category distribution}

In 2019, $57.1 \%$ of adult diagnoses of HIV had a known exposure category $(n=1,203)$. Consistent with previous years, the highest proportion of all reported adult HIV diagnoses in 2019 was among gay, bisexual and other men who have sex with men (gbMSM), at $39.7 \%(n=478)$, although the proportion has decreased over time, particularly since 2015 , when it was $45.0 \%$. Heterosexual contact was reported among $28.3 \%$ $(n=340)$ of cases. The subgroups of the heterosexual contact category followed a consistent pattern, with the proportion of heterosexual contact with no identified risk (Het-NIR) at $10.8 \%$ $(n=130)$, followed by heterosexual contact with a person from an HIV-endemic country (Het-Endemic) at 9.2\% $(n=111)$, and $8.2 \%$ $(n=99)$ attributed to heterosexual contact with a person at risk (Het-Risk). People who inject drugs (PWID) accounted for 21.5\% $(n=259)$ of cases (Table 2).

The exposure category variable was analysed separately for males and females. Among adult males in 2019, gbMSM accounted for the highest proportion $(56.2 \%, n=477)$ of reported cases. Among adult females, exposure through heterosexual contact accounted for the highest proportion at $48.0 \%(n=169)$,
Table 2: Number and proportion of HIV cases ( $\geq 15$ years old) by sex and exposure, Canada (excluding Québec), $2019^{a, b, c, d, e}$

\begin{tabular}{|c|c|c|c|c|c|c|}
\hline \multirow{3}{*}{ Exposure category } & \multicolumn{4}{|c|}{ HIV cases } & \multirow{2}{*}{\multicolumn{2}{|c|}{ Totale }} \\
\hline & \multicolumn{2}{|c|}{ Male } & \multicolumn{2}{|c|}{ Female } & & \\
\hline & $n$ & $\%$ & $n$ & $\%$ & $n$ & $\%$ \\
\hline gbMSM & 477 & 56.2 & N/A & N/A & 478 & 39.7 \\
\hline gbMSM/PWID & 41 & 4.8 & $\mathrm{~N} / \mathrm{A}$ & $\mathrm{N} / \mathrm{A}$ & 41 & 3.4 \\
\hline PWID & 124 & 14.6 & 135 & 38.4 & 259 & 21.5 \\
\hline Heterosexual contact & 170 & 20.0 & 169 & 48.0 & 340 & 28.3 \\
\hline Het-Endemic & 36 & 4.2 & 75 & 21.3 & 111 & 9.2 \\
\hline Het-Risk & 51 & 6.0 & 47 & 13.4 & 99 & 8.2 \\
\hline Het-NIR & 83 & 9.8 & 47 & 13.4 & 130 & 10.8 \\
\hline Other & 37 & 4.4 & 48 & 13.6 & 85 & 7.1 \\
\hline Subtotal ${ }^{\mathrm{b}}$ & 849 & 100.0 & 352 & 100.0 & 1,203 & 100.0 \\
\hline No identified risk ${ }^{c}$ & 51 & 3.5 & 26 & 4.1 & 77 & 3.7 \\
\hline $\begin{array}{l}\text { Exposure category } \\
\text { unknown or not } \\
\text { reported ("missing")d }\end{array}$ & 574 & 38.9 & 252 & 40.0 & 828 & 39.3 \\
\hline Total & 1,474 & N/A & 630 & N/A & 2,108 & N/A \\
\hline
\end{tabular}

Abbreviations: gbMSM, gay, bisexual and other men who have sex with men; Het-Endemic, heterosexual contact with a person from an HIV-endemic country; Het-Risk, heterosexual contact with a person at risk; Het-NIR, heterosexual contact with no identified risk; HIV, human immunodeficiency virus; N/A, not applicable; PWID, people who inject drugs

a Includes cases from Alberta identified through Immigration Refugees and Citizenship Canada, blood/blood products, perinatal, occupational exposure and other exposure categories

b Proportions are based on the subtotal count for known exposure category

c No identified risk: Used when the history of exposure to HIV through any of the other modes listed is unknown, or there is no reported exposure history (e.g. because of death or loss to

follow-up)

follow-up)
$d$ information was not submitted by Québec, new HIV diagnoses reported by Québec are included here

e Total cases includes transsexual, transgender and cases where sex was not reported, whereas "male" and "female" columns exclude these cases

with $21.3 \%$ Het-Endemic $(n=75)$ and $13.4 \%$ Het-Risk and Het-NIR each ( $n=47$ each). In addition, PWID accounted for a little over one-third of adult female HIV cases $(38.4 \%, n=135)$ compared to $14.6 \%(n=124)$ of adult males cases (Table 2$)$.

The distribution for exposure categories in males and females for the last 10 years is shown in Figure 5. In males, the distribution of HIV infection within the different exposure categories fluctuated slightly since 2010 but remained relatively stable overall. Of note, the gbMSM and heterosexual exposure categories decreased slightly in the last 10 years (percent decrease $26.3 \%$ and $27.0 \%$, respectively), while the PWID exposure category remained relatively stable. Exposure attributed to the gbMSM/PWID category increased in the last 10 years (percent increase 10.9\%). In females, there was a considerable decrease in the exposure attributed to heterosexual contact (percent decrease 20.3\%), while the PWID increased (percent increase 32.4\%).

\section{Exposure category distribution by age group}

In 2019, of HIV diagnoses with known exposure category, the highest proportion of gbMSM and gbMSM/PWID were in the 20 to 29 -year age group at $35.1 \%(n=168)$ and $41.5 \%(n=17)$, respectively. Among PWID, the highest proportion $(35.1 \%, \mathrm{n}=91)$ 
Figure 5: Percentage distribution of HIV cases among (a) males and (b) females ( $\geq 15$ years old) by exposure category and year of diagnosis, Canada, 2010-2019a,b

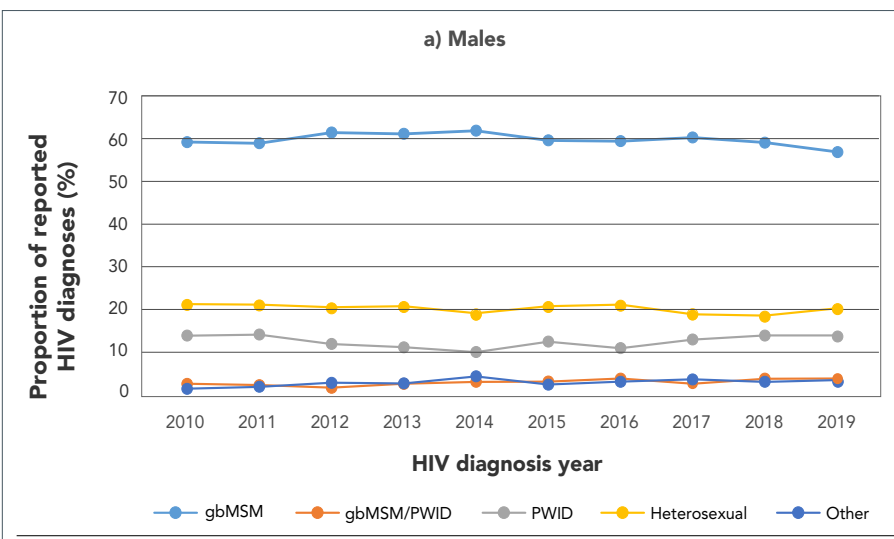

b) Females

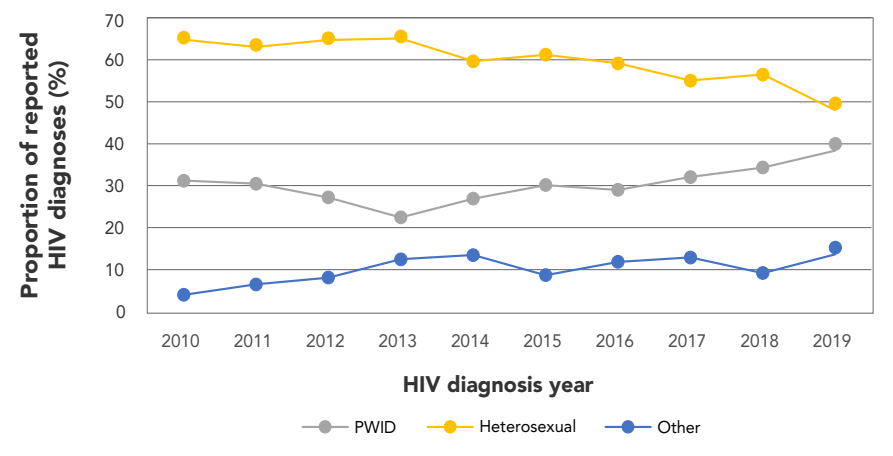

Abbreviations: gbMSM, gay, bisexual and other men who have sex with men; gbMSM/PWID gay, bisexual and other men who have sex with men and use injection drugs; HIV, human immunodeficiency virus; PWID, people who inject drugs

a Excludes cases with no identified risk, unknown exposure category and cases reported by Québec

b Other includes cases from Alberta identified through Immigration Refugees and Citizenship Canada, blood/blood products, perinatal, occupational exposure and other exposure categories

was in the 30 to 39-year age group. Cases reported within the heterosexual contact exposure category were evenly distributed across the different age groups for those aged over 20 years (range: $21.5 \%-26.8 \%$ ), with the highest proportion in the 30 to 39-year age group (Figure 6).

\section{Immigration medical screening for HIV}

Between 2010 and 2019, a total of 4,090 individuals tested positive for HIV on an IME conducted in Canada, at an average of 409 per year (range: 210-696) (Figure 7). A total of 1,188 migrants tested positive for HIV through an IME in 2019. Of these cases, $52.7 \%(n=626)$ cases were tested in Canada and $47.3 \%(n=562)$ were tested overseas prior to their arrival in Canada.

In 2019, of the applicants tested in Canada, a slightly higher proportion of men (54.6\%) than of women tested positive on an IME. Those in the 30 to 39 -year age group had the highest proportion of positive tests (36.1\%), followed by those in the 40 to 49 -year age group (26.8\%). HIV-positive applicants younger
Figure 6: Proportion of reported HIV cases ( $\geq 15$ years old) by exposure category and age group, Canada, $2019 \mathrm{a}, \mathrm{b}, \mathrm{c}$

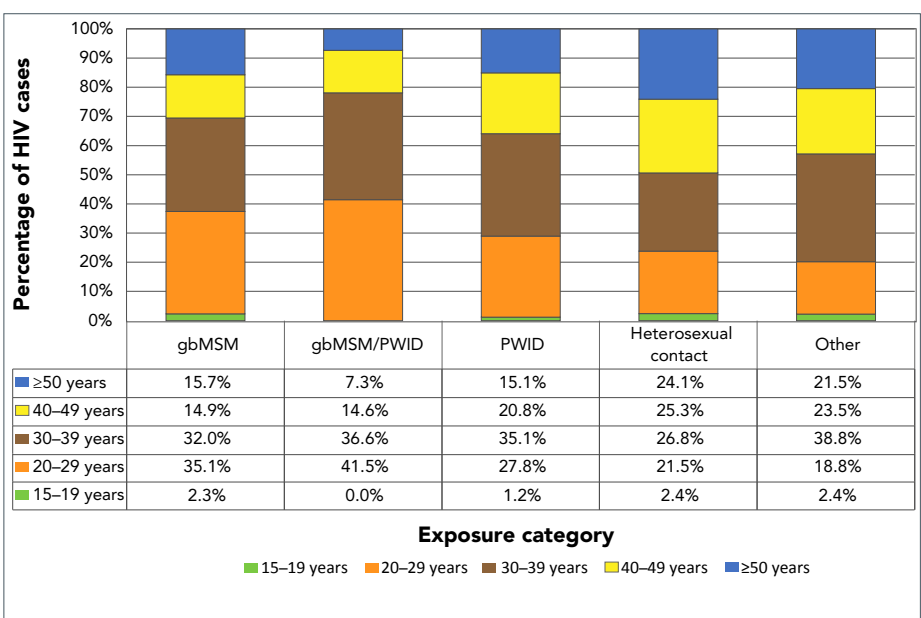

Abbreviations: gbMSM, gay, bisexual and other men who have sex with men; gbMSM/PWID gay, bisexual and other men who have sex with men and use injection drugs; HIV, human immunodeficiency virus; PWID, people who inject drugs

a Includes cases where sex was transsexual, transgender and not reported

b Excludes cases where exposure category was not reported

c Other exposure category includes cases from Alberta identified through Immigration Refugees and Citizenship Canada, blood/blood products, perinatal, occupational exposure and other exposure categories

Figure 7: Number of migrants who tested positive for HIV during an Immigration Medical Exam conducted in Canada, 2010-2019

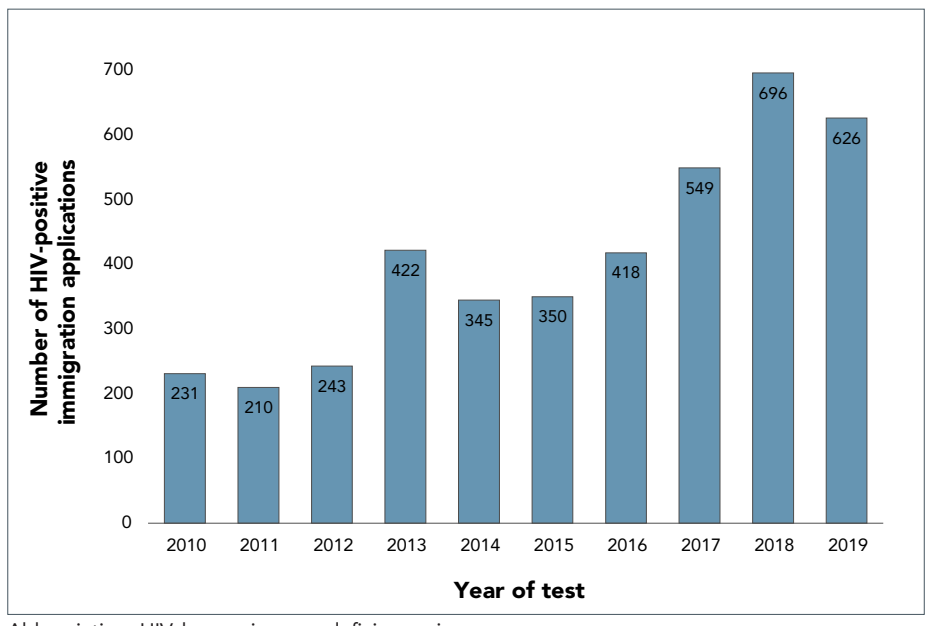

Abbreviation: HIV, human immunodeficiency virus

than 29 years old accounted for $22.2 \%$ of the total, whereas those in the 50-year-plus age group only accounted for $14.9 \%$ of HIV-positive applicants tested in Canada. The majority of in-Canada HIV-positive applicants were in Ontario (57.0\%) and Québec (24.6\%). Among the HIV-positive applicants tested in Canada, $65.7 \%$ were from an HIV-Endemic country.

In 2019, IRCC public health notifications were most commonly sent to Ontario (35.7\%), Québec (28.0\%), Alberta (18.9\%) and British Columbia (8.4\%). 
Canadian Perinatal HIV Surveillance Program

According to CPHSP, 250 infants were perinatally exposed to HIV in Canada in 2019. One infant tested positive for HIV in 2019. This infant was asymptomatic and born from a mother who did not receive antepartum or intrapartum ART prophylaxis. Since 2012, there have been an average of 250 perinatal exposures per year (range: 217-268) with an average of 5.5 confirmed infections per year (range: 1-12). The trend in proportion of HIVpositive mothers receiving ART each year has been increasing since 2015 (93.5\%), with 96.2\% receiving ART in 2018 and 98.0\% in 2019.

The most commonly reported exposure category for HIV-positive mothers in 2019 continued to be heterosexual contact (77.0\%), followed by injection drug use (16.7\%). The most commonly reported maternal race/ethnicity was Black (58.4\%). This was followed by mothers identifying as Indigenous (20.4\%) and White (13.2\%). Most HIV-positive mothers were of African (48.0\%) or North American (34.8\%) origin.

\section{Discussion}

Altogether 2,122 HIV diagnoses were reported in 2019 in Canada, and the national diagnosis rate was 5.6 per 100,000 population. Over the past decade, the rates have remained stable over time, with some minor fluctuations. The 2019 diagnosis rate was slightly lower than that in 2018; more time and data are needed to determine whether this decrease is the beginning of a continuing trend.

A total of 1,188 migrants tested positive for HIV on an IME in 2019. Of these cases, $52.7 \%$ cases were tested in Canada and $47.3 \%$ were tested overseas prior to their arrival in Canada. There were 250 infants perinatally exposed to HIV in Canada in 2019. The one documented perinatal HIV transmission was related to a mother who did not receive antepartum or intrapartum ART prophylaxis.

As in previous years, gbMSM remained the largest proportion of new HIV diagnoses and accounted for over half of adult male cases (56.2\%) in 2019. A slight decrease has been noted in rates among males overall since 2016 and in HIV diagnoses among gbMSM since 2017. This decrease in rates in males overall coincides with Health Canada's approval of PrEP, and may reflect the impact of this new HIV prevention technology in this population. This trend echoes that seen in other developed countries, including Australia and the United Kingdom $(14,15)$. In Australia, there has been a decrease of $25.4 \%$ in HIV diagnosis among gbMSM since 2016. In the United Kingdom, there has been a decrease of $47.1 \%$ since 2014 , a change attributed to a significant decline in HIV diagnoses among gay and bisexual men. As PrEP uptake increases in eligible populations, further reductions in HIV diagnosis may be expected.
The decrease in HIV diagnosis in Canada was not as great as that seen in other countries. This indicates that more can be done to increase awareness and use of PrEP. Based on the results of a 2017 survey of gbMSM in Canada, 51.7\% of participants reported that they were likely to use PrEP if affordable and available, and only $8.4 \%$ were using PrEP at the time of the survey (16).

The rates of diagnosis in females have increased slightly since 2015. This trend coincides with increasing cases of infectious syphilis in women (17). These overall trends suggest increases in substance use, injection drug use and prevalence of STBBIs in some networks of women at risk for STBBI. These trends also provide additional support for the integrated national approach articulated by the Government of Canada's framework (4) to reduce the health impact of STBBIs in Canada in key populations affected by overlapping epidemics (i.e. syndemics) (18). This increase in rates among women was not observed in other developed countries where information was available. In fact, the rates among women decreased in the United States between 2014 and 2018, with the exception of a slight increase (8\%) since 2014 in case counts in women who inject drugs (19). Likewise, in Australia, the rates of HIV diagnoses in females decreased slightly since 2017 (14), while the United Kingdom has shown a consistent annual decrease in new HIV diagnoses counts in females since 2010 (15).

Nearly one-fourth of HIV diagnoses in 2019 were attributed to Indigenous peoples, indicating an overrepresentation of this population in Canadian HIV data. Given that only a limited number of jurisdictions report Indigeneity, these proportions are likely biased. However, it is clear that Indigenous peoples are overrepresented among those living with HIV. New estimates, which rely on HASS data, along with other sources of data indicate that infections among Indigenous people represented $14 \%$ of all new infections in 2018 , whereas Indigenous people represented only $4.9 \%$ of the total Canadian population (2).

Data from IRCC indicate that while the proportion of migrants with positive HIV test results on their IME has remained relatively stable in recent years, the overall number of people migrating to Canada has increased. However, the number of HIV diagnoses identified through IMEs does not necessarily reflect new HIV cases in Canada. Some migrants who tested HIV positive in overseas IMEs may not arrive in Canada, and those identified during in-Canada IMEs may already be accounted for in provincial/territorial reports. Furthermore, it would be difficult to ascertain the timing of HIV acquisition of the 626 migrants who tested positive during in-Canada IMEs in 2019. More information is needed to better understand the epidemiology of HIV among new Canadians, particularly among those from HIV-endemic countries.

In 2019, there were 250 infants perinatally exposed to HIV in Canada. One mother-to-child HIV transmission was confirmed in a mother who did not receive antepartum or intrapartum 
ART. Over the years, important mitigation measures have been taken in Canada to prevent mother-to-child HIV transmission. These include an increased access to antenatal care, routine HIV screening of pregnant women and availability of treatment for HIV-positive mothers. Nevertheless, missed opportunities for prevention continue to occur, primarily in vulnerable populations, leading to a small number of perinatal infections (20).

Despite advances in the prevention, diagnosis and treatment of HIV, HIV and other STBBIs remain a significant health concern in Canada. Surveillance data, such as those presented in this report, are a key component in understanding the burden of STBBI in Canada and to monitor Canada's progress toward the stated goals of the framework (4).

\section{Strengths and limitations}

The main strength of this report is that it is the only source of national epidemiological data on all reported HIV diagnoses in Canada. It also incorporates data on HIV diagnoses among migrants to Canada and perinatal transmission of HIV, which help build a more complete picture of the state of HIV in Canada.

Limitations of HASS have been described previously $(10,12)$ and are common to most surveillance systems. While it is difficult to ascertain the factors that may contribute to noted fluctuations, changes in reporting practices by provincial and territorial health authorities may have had an impact.

The low completion rate of data elements related to the race/ethnicity and exposure setting of new HIV cases, and the resulting potential biases in the available data, create difficulties in making inferences about the factors that influence HIV transmission in Canada. PHAC continues to work with its surveillance partners to enhance the collection of data elements including race/ethnicity information.

As reported by Popovic et al. (21), HIV cases reported by provinces and territories through routine surveillance mechanisms may have been previously diagnosed, either in another Canadian jurisdiction or in another country; such cases affect observed trends in HIV diagnosis rates. Therefore, it is important to understand the overall burden of HIV infection in people currently living in Canada.

\section{Conclusion}

The data in this report are considered provisional and may be subject to change in future HIV surveillance reports. If discrepancies exist between the data summarized in this report and provincial and territorial reports, the most recent provincial and territorial report should be used.

\section{Authors' statement}

$\mathrm{NH}$ - Conceptualization, research, writing, original draft, final draft, review, editing, data validation, visualization, supervision AW - Data validation, original draft, editing, research AR - Data management, data validation, research ST - Review, editing

\section{Competing interests}

None.

\section{Acknowledgements}

The Public Health Agency of Canada (PHAC) would like to acknowledge the following individuals from the provincial and territorial HIV/AIDS programs for their contribution and participation: S Fathima, Alberta Health; A O'Brien, Alberta Health; J Wong, Clinical Prevention Service, Surveillance and Epidemiology, BC Centre for Disease Control; C Loeppky, Manitoba Health; R RaaFat Gad, New Brunswick Department of Health; S Landsburg, New Brunswick Department of Health; S Wertz, New Brunswick Department of Health; B Halfyard, Department of Health and Community Services, Newfoundland and Labrador; M O'Driscoll, Department of Health and Community Services, Newfoundland and Labrador; H Hannah, Department of Health and Social Services, Northwest Territories; B Billard, Nova Scotia Department of Health and Wellness; S Fleming, Nova Scotia Department of Health and Wellness; K Kullerperuma, Nunavut Department of Health; A Kroch, Ontario Treatment Network; J Liu, Public Health Ontario; Dr. M Murti, Public Health Ontario; Dr. M. Cameron, Prince Edward Island Department of Health and Wellness; C Cheverie, Prince Edward Island Department of Health and Wellness; $\mathrm{R}$ Bitera, Direction des risques biologiques et de la santé au travail, Institut national de santé publique du Québec; PH Minot, Direction des risques biologiques et de la santé au travail, Institut national de santé publique du Québec; B Serhir, Laboratoire de santé publique du Québec, Institut national de santé publique du Québec; D Sylvain, Laboratoire de santé publique du Québec, Institut national de santé publique du Québec; H Bangura, Saskatchewan Ministry of Health; J Manalo, Saskatchewan Ministry of Health; L Strudwick, Yukon Communicable Disease Control; S Plitt, PHAC, Alberta; E Wong, PHAC, British Columbia; J Paul, PHAC, Manitoba; A Sullivan, PHAC, Ontario; T Schellenberg, PHAC, Saskatchewan; M Nichols, PHAC, Nova Scotia; A Bitnun and L Sauvé, Canadian Perinatal HIV Surveillance Program (CPHSP); C Rank, A Grundy and C Nwoke, Immigration, Refugees and Citizenship Canada (IRCC).

\section{Funding}

This work was supported by the Public Health Agency of Canada as part of its core mandate. 


\section{References}

1. The Joint United Nations Programme on HIV/AIDS. UNAIDS data 2020. Geneva (CH): UNAIDS; 2020. https://www.unaids.org/sites/ default/files/media_asset/2020_aids-data-book_en.pdf

2. Public Health Agency of Canada. Estimates of HIV incidence, prevalence and Canada's progress on meeting the 90-90-90 HIV targets, 2018. Ottawa (ON): PHAC; 2020 (accessed 202012-17). https://www.canada.ca/en/public-health/services/ publications/diseases-conditions/summary-estimates-hiv-incidenc e-prevalence-canadas-progress-90-90-90.html

3. Public Health Agency of Canada. Population-specific HIV/ AIDS status report: people living with HIV/AIDS. Ottawa (ON): PHAC; 2013 (accessed 2020-12-17). https://www.canada.ca/en/ public-health/services/hiv-aids/publications/population-specifi c-hiv-aids-status-reports/people-living-hiv-aids.html

4. Public Health Agency of Canada. Reducing the health impact of sexually transmitted and blood-borne infections in Canada by 2030: a pan-Canadian STBBI framework for action. Ottawa (ON): PHAC; 2019 (accessed 2020-12-17). https://www.canada. ca/en/public-health/services/infectious-diseases/sexual-healt h-sexually-transmitted-infections/reports-publications/ sexually-transmitted-blood-borne-infections-action-framework. html

5. Public Health Agency of Canada. Accelerating our response: Government of Canada five-year action plan on sexually transmitted and blood-borne infections. Ottawa (ON): PHAC. 2019 (accessed 2020-12-17). https://www.canada.ca/en/ public-health/services/reports-publications/accelerating-ou r-response-five-year-action-plan-sexually-transmitted-bloo d-borne-infections.html

6. Cohen MS, Chen YQ, McCauley M, Gamble T, Hosseinipour MC, Kumarasamy N, Hakim JG, Kumwenda J, Grinsztejn B, Pilotto JH, Godbole SV, Mehendale S, Chariyalertsak S, Santos BR, Mayer KH, Hoffman IF, Eshleman SH, Piwowar-Manning E, Wang L, Makhema J, Mills LA, de Bruyn G, Sanne I, Eron J, Gallant J, Havlir D, Swindells S, Ribaudo H, Elharrar V, Burns D, Taha TE, Nielsen-Saines K, Celentano D, Essex M, Fleming TR; HPTN 052 Study Team. Prevention of HIV-1 infection with early antiretroviral therapy. N Engl J Med 2011;365(6):493-505.

DOI PubMed

7. Marks G, Crepaz N, Senterfitt JW, Janssen RS. Meta-analysis of high-risk sexual behavior in persons aware and unaware they are infected with HIV in the United States: implications for HIV prevention programs. J Acquir Immune Defic Syndr 2005;39(4):446-53. DOl PubMed

8. Metsch LR, Pereyra M, Messinger S, Del Rio C, Strathdee SA, Anderson-Mahoney P, Rudy E, Marks G, Gardner L; Antiretroviral Treatment and Access Study (ARTAS) Study Group. HIV transmission risk behaviors among HIV-infected persons who are successfully linked to care. Clin Infect Dis 2008;47(4):577-84. DO PubMed

9. Antiretroviral Therapy Cohort Collaboration. Life expectancy of individuals on combination antiretroviral therapy in high-income countries: a collaborative analysis of 14 cohort studies. Lancet 2008;372(9635):293-9. DOI PubMed

10. Haddad N, Robert A, Weeks A, Popovic N, Siu W, Archibald C. HIV in Canada-surveillance report, 2018. Can Commun Dis Rep 2019;45(12):304-12. DOI PubMed
11. Public Health Agency of Canada. Case Definitions for communicable diseases under national surveillance -2009 . Results of Provincial/Territorial (P/T) Consultation Process. Can Commun Dis Rep 2009;35S2:S1-123. https://www.canada.ca/content/dam/ phac-aspc/migration/phac-aspc/publicat/ccdr-rmtc/09pdf/35s2eng.pdf

12. Public Health Agency of Canada. HIV and AIDS in Canada: surveillance report to December 31, 2014. Ottawa (ON): PHAC; 2015. https://www.canada.ca/en/public-health/services/ publications/diseases-conditions/hiv-aids-canada-surveillanc e-report-december-31-2014.html

13. Statistics Canada. Annual demographic estimates: Canada, provinces and territories, 2019. Ottawa (ON): StatsCan; 2019 (accessed 2020-12-17). https://www150.statcan.gc.ca/n1/pub/91215-x/91-215-x2019001-eng.htm

14. The Kirby Institute. National HIV notifications. Q1 2015-Q4 2019. Kensington (AU): The Institute; 2019. https://kirby.unsw.edu.au/ sites/default/files/kirby/report/National-HIV-Quarterly-Report_20 19-Q4.pdf

15. Public Health England. Trends in HIV testing, new diagnoses and people receiving HIV-related care in the United Kingdom: data to the end of December 2019. Health Protection Report 2020;14(20):1-15. https://assets.publishing.service.gov.uk/ government/uploads/system/uploads/attachment_data/ file/939478/hpr2020_hiv19.pdf

16. Brogan N, Paquette DM, Lachowsky NJ, Blais M, Brennan DJ, Hart TA, Adam B. Canadian results from the European Men-who-have-sex-with-men Internet survey (EMIS-2017). Can Commun Dis Rep 2019;45(11):271-82. DOI PubMed

17. Infectious syphilis cases reported in Canada 2009-2018. Infographic. Can Commun Dis Rep 2020;45(11):302. https://www.canada.ca/en/public-health/services/ reports-publications/canada-communicable-disease-report-ccdr/ monthly-issue/2019-45/issue-11-november-7-2019/article5-infectious-syphilis-canada-2009-2018.html

18. Murti M, Wong J, Whelan M, Renda C, Hohenadel K, Macdonald $L$, Parry D. The need for integrated public health surveillance to address sexually transmitted and blood-borne syndemics. Can Commun Dis Rep 2019;45(2-3):63-6.

DOI PubMed

19. Centers for Disease Control and Prevention. Diagnoses of HIV infection in the United States and Dependent Areas. HIV Surveillance Report. Atlanta (GA): National Center for HIV/AIDS, Viral Hepatitis, STD, and TB Prevention, CDC; 2018 (modified 2020-05-07; accessed 2020-09-01). https://www.cdc.gov/hiv/ library/reports/hiv-surveillance/vol-31/index.html

20. Bitnun A, Lee T, Brophy J, Samson LM, Kakkar F, Vaudry W, Tan B, Money DM, Singer J, Sauvé LJ, Alimenti A; Canadian Perinatal HIV Surveillance Program. Missed opportunities for prevention of vertical HIV transmission in Canada, 1997-2016: a surveillance study. CMAJ Open 2018;6(2):E202-10. DOI PubMed

21. Popovic N, Yang Q, Haddad N, Weeks A, Archibald C. Improving national surveillance of new HIV diagnoses. Can Commun Dis Rep 2019;45(12):313-6. DOI PubMed 


\section{Appendix: List of supplementary tables}

These tables are available upon request at:

phac.hass.aspc@canada.ca

Table S1: HIV diagnosis rate (per 100,000 population) by province/territory and year of diagnosis (all ages)

Table S2: Number of HIV cases (all ages) by province/territory, sex and year of diagnosis-Canada, 1985-2019

Table S3: Number of HIV cases by age group and province/territory-Canada, 2018-2019

Table S4: Cumulative number of HIV cases among adults ( $\geq 15$ years old) and children ( $<15$ years old) by sex-Canada, 1985-2019

Table S5: Number of HIV cases among adults ( $\geq 15$ years old) by year of diagnosis and sex-Canada, 1985-2019

Table S6: Number of cases and HIV diagnosis rate by age group, sex and year of diagnoses-Canada, 1985-2019

Table S7: Number and percentage distribution of HIV cases among adults ( $\geq 15$ years old) by exposure category and year of diagnosis-Canada, 1985-2019

Table S8: Number and percentage distribution of HIV cases among adult males ( $\geq 15$ years old) by exposure category and year of diagnosis-Canada, 1985-2019

Table S9: Number and percentage distribution of HIV cases among adult females ( $\geq 15$ years old) by exposure category and year of diagnosis-Canada, 1985-2019

Table S10: Number and percentage distribution of HIV cases among adults ( $\geq 15$ years old) by exposure category and age group-Canada, 2018-2019
Table S11: Number and percentage distribution of HIV cases among children ( $<15$ years old) by exposure category and year of diagnoses-Canada, 1985-2018

Table S12: Number of HIV cases by exposure category and province/territory-Canada, 2018-2019

Table S13: Number and percentage distribution of immigration applicants to Canada diagnosed with HIV as a result of an Immigration Medical Exam by year-2002-2019

Table S14: Number and percentage distribution of immigration applicants to Canada diagnosed with HIV as a result of an Immigration Medical Exam by sex, age group and province-2012-2019

Table S15: Number of perinatally HIV-exposed infants by year of birth, current status and use of antiretroviral therapy for prophylaxis-Canada, 1984-2019

Table S16: Number of perinatally HIV-exposed infants by maternal exposure category and year of infant birth-Canada, 1984-2019

Table S17: Number of perinatally HIV-exposed infants by ethnic status and infection status-Canada, 1984-2019

Table S18: Number of perinatally HIV-exposed infants by maternal country of birth and infection status-Canada, 1984-2019

Table S19: Number of perinatally HIV-exposed infants by geographic region and status at last report-Canada, 1984-2019

Table S20: International statistics on reported HIV cases-Canada, 2018 